\title{
THE INFLUENCE OF CRYSTALLOGRAPHIC TEXTURE ON DYNAMIC RECRYSTALLIZATION
}

\author{
R. KAIBYSHEV ${ }^{\mathrm{a}, *}$, B. SOKOLOV ${ }^{\mathrm{b}}$ and A. GALIYEV ${ }^{\mathrm{a}}$ \\ ${ }^{a}$ Institute for Metals Superplasticity Problems RAS, 39 Khalturina, 450001, \\ Ufa, Russia; ${ }^{\mathrm{b}}$ Institute of Metal Physics UB RAS, 18 Kovalevskaya, 620219, \\ Ekaterinburg, Russia
}

(Received in final form 28 September 1997)

The influence of a crystallographic texture (CT) on Dynamic Recrystallization (DRX) was investigated at $T=300^{\circ} \mathrm{C}$ and $\dot{\varepsilon}=2.8 \times 10^{-3} \mathrm{~s}^{-1}$ in $\mathrm{Mg}-5.8 \% \mathrm{Zn}-0.65 \% \mathrm{Zr}$ in detail. It was shown that mechanics and kinetics of DRX are in strong dependence on location of basal planes. Initial texture effects recrystallized grain size too. Extensive recrystallization process was observed in cases when basal planes locate parallelly or at right angles to a compression axis. Almost full recrystallization structure was formed after moderate strains. If basal planes locate at $45^{\circ}$ to the compression axis DRX occurs slowly and the formed grain size is less as compared to the other two cases. Microstructure evolution was considered in context of relationship between DRX and mechanisms of plastic deformation. It was established that the effect of initial texture on DRX is promoted by its influence on the character of dislocation slip. The reasons for the influence of the character of dislocation slip on DRX are discussed.

Keywords: Crystallographic texture; Dynamic recrystallization; Deformation mechanism

\section{INTRODUCTION}

It is now known that structural factors strongly influence the dynamic recrystallization (DRX) of various metals (Sah et al., 1974; Maki et al., 1982; Ouchi and Okita, 1982; Sakai and Jonas, 1984; Kaibyshev et al., 1994). On the other hand, it was shown in the works by Grabski (1972), Pickence et al. (1987), Kaibyshev and Sitdikov (1991),

\footnotetext{
*Corresponding author. Fax: 7-(3472) 253-759. E-mail: rustam@metal.ugatu.ac.ru.
} 
Belyakov et al. (1995) that plastic deformation mechanisms affect the phenomenology and kinetics of DRX. In turn, the material structure influences the deformation mechanisms (Kaibyshev, 1992). Therefore, the influence of structure on DRX is caused by dependence of deformation mechanisms on material structure.

Among structural factors the crystallographic texture (CT) has the strongest influence on the deformation mechanisms (Kaibyshev, 1992). Therefore, CT affects DRX. In the work by Bakhteeva et al. (1982) it was found that the orientation of a monocrystal in a direction favorable for easy slip retards the formation of recrystallized grains during deformation and lowers the level of flow.stresses. Unfortunately, the influence of CT on the phenomenology and kinetics of DRX was not investigated in literature.

The purpose of the present work was to investigate the influence of the CT on DRX. As the object, we selected the magnesium alloy MA14, which is almost an ideal material for studying various aspects of plastic deformation (Kaibyshev et al., 1985; Kaibyshev, 1992).

\section{EXPERIMENTAL}

The material used for the study was the MA14 magnesium alloy $(5.8 \%$ $\mathrm{Zn}, 0.65 \% \mathrm{Zr}$, and $\mathrm{Mg}$ the balance). The starting material was a hotpressed rod, $90 \mathrm{~mm}$ in diameter, previously annealed for $48 \mathrm{~h}$ at $T=500^{\circ} \mathrm{C}$ so that the average grain size was $d=65 \mu \mathrm{m}$. It had an axial $\langle 11 \overline{2} 0\rangle$ texture with an intensity of 5 or 6 units (relative to a textureless reference specimen) and with a scatter of $20-25^{\circ}$ from the pressing axis. The rod was cut into specimens, $10 \mathrm{~mm}$ in diameter and $12 \mathrm{~mm}$ long. The angle between the pressing axis and the axis of the specimens was $0^{\circ}$ (for state 1 ), $45^{\circ}$ (for state 2), and $90^{\circ}$ (for state 3) (Fig. 1). The specimens were deformed by compression on an Instron Model 1185 universal dynamometer at $T=300^{\circ} \mathrm{C}$ and $\dot{\varepsilon}=2.8 \times 10^{-3} \mathrm{~s}^{-1}$. To fix the structural changes directly associated with hot working, a special setup was used, which provided for the instantaneous quenching of the specimens just as the deformation was finished.

The deformation relief was examined in a JSM-840 scanning electron microscope. The texture was analyzed using direct pole figures (secondorder reflections from the (0001) planes) (Borodkina and Spektor, 


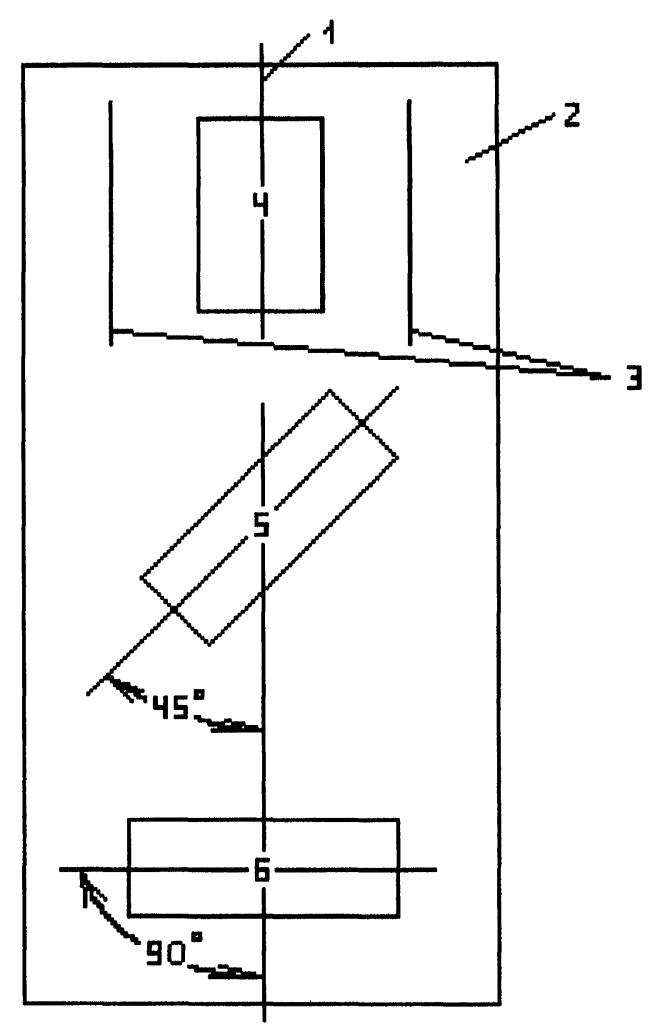

FIGURE 1 Diagram of specimen cutting from MA14 alloy bar: (1) pressing axis, (2) rod, (3) basal plane (the spread of the texture is neglected), (4) state 1 specimens, (5) state 2 specimens, (6) state 3 specimens.

1981). The pole figures were taken from the end faces of the specimens with filtered $\mathrm{Cu}$ radiation using a DRON-3M X-ray diffractometer. The TEM observations were carried out by a JEOL JEM-2000EX transmission electron microscope at acceleration voltage of $200 \mathrm{kV}$. The Kikuchi-line method was applied to analyze misorientation angles of grain boundaries (Valiev et al., 1991). A microdiffraction and a dark field were used in order to find the Burgers vector of lattice dislocations by the criterion $\boldsymbol{g} \cdot \boldsymbol{b}=0$ (Bushnev et al., 1989).

The apparent activation energy of plastic deformation was determined using the procedure described by Pickence et al. (1987), and the stress exponent $n$ was found from the slope of the $\log \varepsilon-\log \sigma$ curves (Cadek, 1984). 


\section{RESULTS}

\section{Mechanical Behavior}

It can be seen from the mechanical tests (Fig. 2, Table I) that the mechanical properties of the MA14 alloy depend on CT. The highest flow stress level is in state 3 and the lowest one is in state 2 . An intermediate position of the $\sigma-\varepsilon$ curve takes place in state 1 . At $T=300^{\circ} \mathrm{C}$ and $\dot{\varepsilon}=2.8 \times 10^{-3} \mathrm{~s}^{-1}$ the $\sigma-\varepsilon$ curves of state 1 and 3 specimens have strongly pronounced maxima.

The apparent activation energy and the stress exponent take on a maximum value of $192 \mathrm{~kJ} / \mathrm{mol}$ and 6.2 , respectively, in state 2 (Table I).

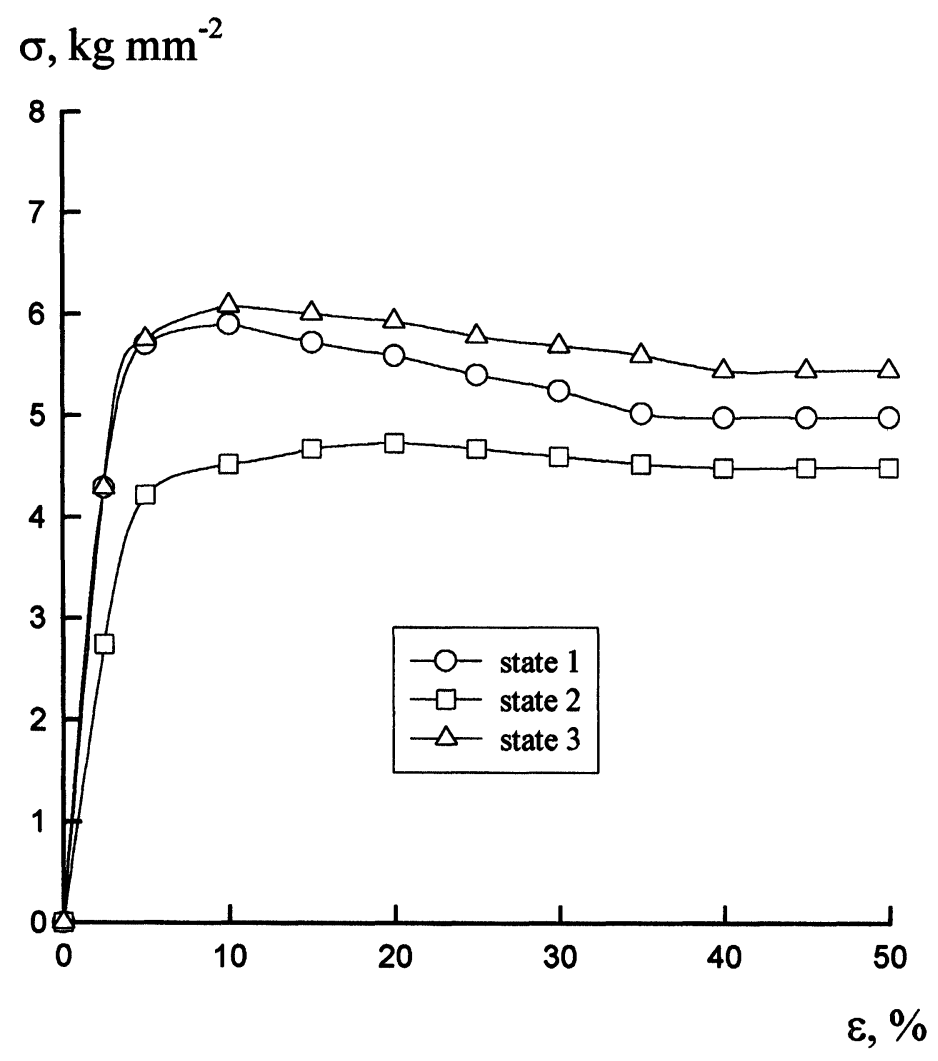

FIGURE 2 The stress-strain curves at $T=300^{\circ} \mathrm{C}$ and $\dot{\varepsilon}=2.8 \times 10^{-3} \mathrm{~s}^{-1}$. 
TABLE I Flow stress exponent $n$ and apparent activation energy $Q^{*}\left(T=300^{\circ} \mathrm{C}\right)$

\begin{tabular}{lccc}
\hline Parameters & \multicolumn{4}{c}{ Angle between the specimen axis and pressing axis } \\
\hline & $0^{\circ}$ & $45^{\circ}$ & $90^{\circ}$ \\
$n$ & 4.8 & 6.2 & 4.9 \\
$Q^{*}, \mathrm{~kJ} / \mathrm{mol}$ & $135 \pm 10$ & $192 \pm 10$ & $132 \pm 10$ \\
\hline
\end{tabular}

It is usually attributed to the cross slip of dislocations from the plane of basic slip to the plane of a cross slip by the Friedel model (Edelin and Poirier, 1973; Vagarli and Langdon, 1981; 1982; Couret and Caillard, 1985; Puschl et al., 1987). For the longitudinal and transverse specimens the values of $Q^{*}$ and $n$ are close. $Q^{*}$ takes on values equal to 135 and $132 \mathrm{~kJ} / \mathrm{mol}$, respectively; these values are close to the activation energy for the self-diffusion of $\mathrm{Mg}(135 \mathrm{~kJ} / \mathrm{mol})$. At the same time, the activation energies are almost the same as the thermal activation energy $(>1.2 \mathrm{eV})$ of cross slip in the nonbasal planes by the Friedel-Escaig mechanism for dislocations with the Burgers vector $\boldsymbol{b}=1 / 3[11 \overline{2} 0]$ (Edelin and Poirier, 1973; Couret and Caillard, 1985) at a given temperature.

\section{The Microstructure}

The results of metallographic analysis also show distinctions in the formation of DRX microstructure in the different states (Fig. 3). The first recrystallized grains are formed on the initial grain boundaries after $\varepsilon \approx 15 \%$ in states 1 and 3 and after $\varepsilon \approx 20 \%$ in state 2 . The maximum rate of DRX takes place in the transverse specimens in early stages of plastic flow $(\varepsilon=15-25 \%)$ and in the longitudinal specimens after $\varepsilon \approx 25 \%$. The recrystallized grain volume after $\varepsilon=50 \%$ is minimum in state 2 and maximum in state 3 . The recrystallized grain size depends on the CT too. After $\varepsilon=50 \%$ the greatest recrystallized grain size is observed in state 3 , it is a bit smaller in state 1 and the minimum value of $d_{\text {rec }}$ is in state 2 .

\section{Deformation Relief}

Topographic observations (Fig. 4) show that the character of slip strongly depends on the CT. It shows that operation of different deformation mechanisms depends on the location of the basal planes with respect to the compression axis. In turn, the difference in 


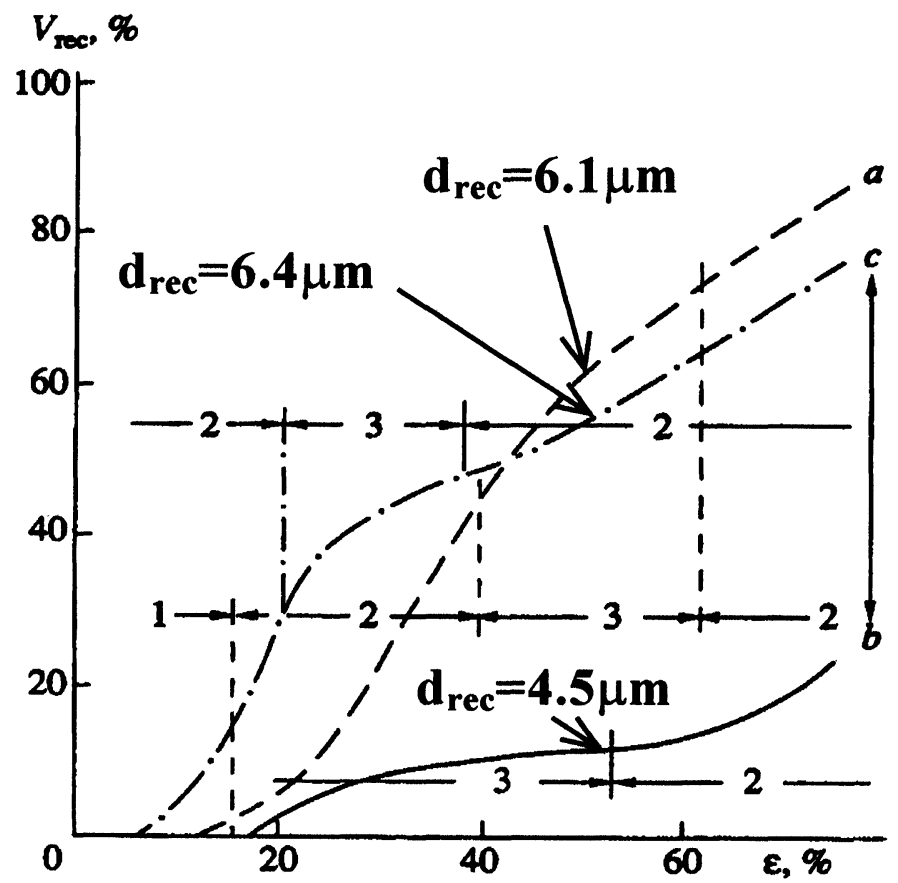

FIGURE 3 Kinetics of DRX plotted against the contributions of the main slip systems to the total deformation: (1) region of an insignificant effect of the $\langle 11 \overline{2} 0\rangle(0001)$ system; (2) region of equal effects of the $\langle 11 \overline{2} 0\rangle(0001)$ and $\langle 11 \overline{2} 0\rangle\{10 \overline{1} 1\}$ systems; (3) region of the predominant effect of the $\langle 11 \overline{2} 0\rangle(0001)$ system: (a) state 1 , (b) state 2, (c) state 3 .

deformation mechanisms causes changes in phenomenology and kinetics of DRX.

In the early stage of plastic flow the deformation relief in specimens 1 is characterized by formation of short $(3-10 \mu \mathrm{m})$ wavy lines. They spread uniformly across the body of the grains, with only a slightly higher density near the initial boundaries. The wavy nature of these slip lines is due to cross slip from one plane into another (Vagarli and Langdon, 1981; Yoo, 1981). The increase in the amount of strain (up to $\varepsilon=60 \%$ ) qualitatively changes the deformation relief pattern. Long and straight lines due to basal slip become predominant and form slip bands, which consist of parallel and interweaving wavy slip lines. 

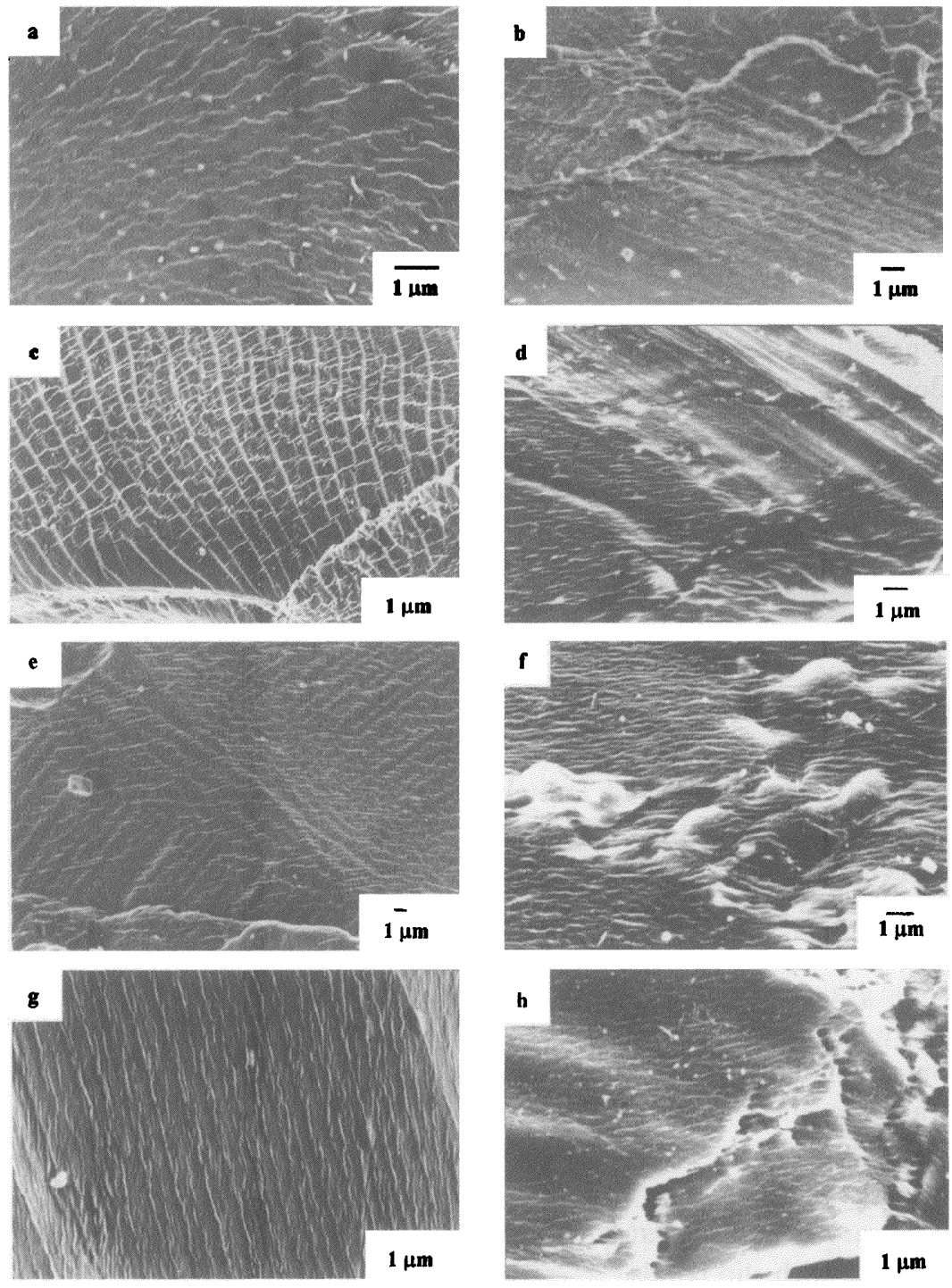

FIGURE 4 Deformation relief at $T=300^{\circ} \mathrm{C}$ and $\dot{\varepsilon}=2.8 \times 10^{-3} \mathrm{~s}^{-1}$ : (a) state 1 , $\varepsilon=12 \%$; (b) state $1, \varepsilon=60 \%$; (c) state $2, \varepsilon=12 \%$; (d) state $2, \varepsilon=35 \%$; (e) state 2 , $\varepsilon=60 \%$; (f) state $2, \varepsilon=80 \%$, (g) state $3, \varepsilon=12 \%$; (h) state $3, \varepsilon=25 \%$. 
In specimens 2 the nature of the deformation relief is entirely different. Coarse, long $(20-80 \mu \mathrm{m})$, straight lines of the basal slip that pass entirely across the grains are predominant in the original state. Slip along the planes of the prism $\{10 \overline{1} 0\}$ is of an accommodational nature; the short $(2-6 \mu \mathrm{m})$ and thick slip lines make an angle of $90^{\circ}$ to the (0001) planes. When the amount of strain is $\varepsilon=35 \%$, the character of slip changes. In nearly $40 \%$ of the grains, the traces of basal slip are transformed into slip bands similar to those observed in the longitudinal specimens. At the same time basal slip remains predominant. Further plastic flow $(\varepsilon=60 \%)$ leads to the disappearance of coarse straight slip lines typical of the $\langle 11 \overline{2} 0\rangle(0001)$ slip system and enhances the homogeneity of slip. The prevailing form is fine slip bands each consisting of a set of short wavy slip lines. As the amount of strain is increased to $\varepsilon=80 \%$, short slip lines appear, uniformly distributed in the bulk of the unrecrystallized regions.

The most complex pattern of the deformation relief is observed in specimens 3 . In the original state the wavy slip traces with short (1$2 \mu \mathrm{m}$ ) lines at angles of approximately $30^{\circ}$ and $60^{\circ}$ to the main slip lines testify that slip occurs along basal, prismatic, and first kind pyramidal planes (Predvoditelev and Troitskii, 1973). In contrast to specimens 2, it is difficult to distinguish any one of the systems as predominant, especially near the initial boundaries in specimens 3 . The amounts of strain $\varepsilon=25 \%$ have the strongest effect on the character of slip. The uniformity of slip decreases. The basal slip becomes more active. In some grains, traces of the basal slip transform to wavy slip lines from 2 to $5 \mu \mathrm{m}$ long. As the amount of strain is increased to $\varepsilon=60 \%$, half of the original grains are already covered by a uniform network of fine wavy slip lines.

The relief in the recrystallized grains in all states is basically formed by short wavy slip lines uniformly distributed in the bulk of grains. It is necessary to notice that some boundaries of the recrystallized grains coincide with slip bands.

\section{Electron Microscopy}

TEM analysis shows (Fig. 5) that different slip systems operate depending on the texture of the alloy. The study of the fine structure after low strain reveals that $1 / 3\langle 11 \overline{2} 0\rangle\{10 \overline{1} 0\}$ dislocations predominate 

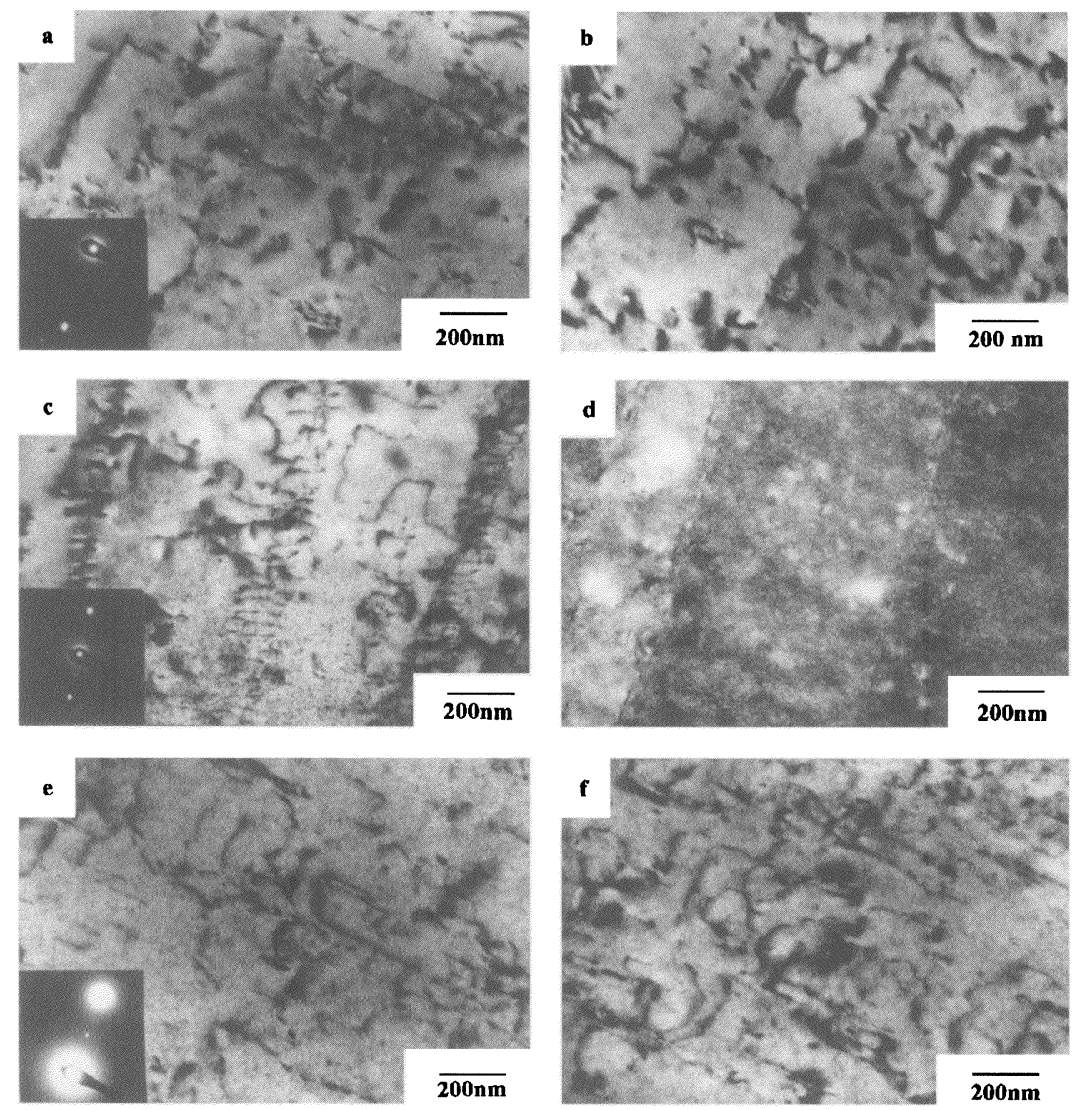

FIGURE 5 TEM microstructures: $(\mathrm{a}, \mathrm{b})$ state 1 ; $(\mathrm{c}, \mathrm{d})$ state 2, $(\mathrm{e}, \mathrm{f})$ state 3; (d) dark field.

in the state 1 specimens. $1 / 3\langle 11 \overline{2} 0\rangle(0001)$ dislocations are extremely rarely found in this state. In some places dislocation walls are observed, which consist of the $1 / 3\langle 11 \overline{2} 0\rangle\{10 \overline{1} 1\}$ dislocations. In the state 2 specimens two basic types of dislocations appear: $1 / 3\langle 11 \overline{2} 0\rangle(0001)$ and $1 / 3\langle 11 \overline{2} 0\rangle\{10 \overline{1} 0\}$. As a rule, prismatic dislocations draw up in flat pileups parallel to each other, however individual curved dislocations occur out of the pileups. In state 3 specimens the most complex pattern of dislocation structure is observed. Simultaneously, three types of $\langle 11 \overline{2} 0\rangle$ dislocations can be found: long basal, short prismatic on planes perpendicular to the basal one, and curved first kind pyramidal. 


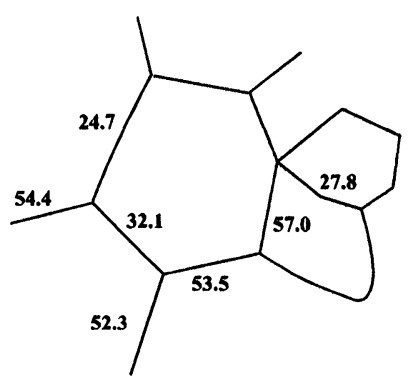

a

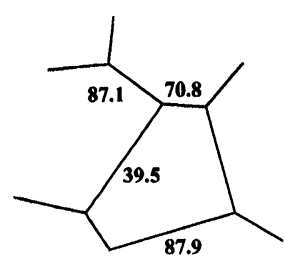

b

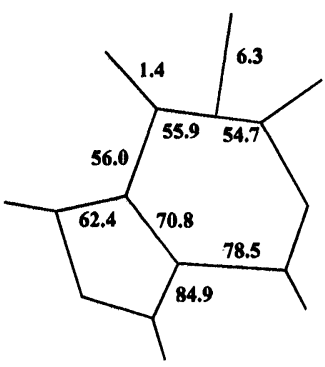

c

FIGURE 6 Boundary misorientation in the region of recrystallized structure ((a) state $1, \varepsilon=40 \%$; (b) state $2, \varepsilon=75 \%$; (c) state $3, \varepsilon=40 \%$ ).

As compared to the state 1 and 2 specimens, dislocations are most uniformly distributed throughout the body of the grain in the state 3 specimens.

Figure 6 shows the region of recrystallized structure after strain $\varepsilon=40 \%$ in the longitudinal and transverse specimens and after strain $\varepsilon=75 \%$ in specimens 2 . It can be seen that low angle grain boundaries are contained in the unrecrystallized region in the state 3 specimens. At the same time, some misorientations are close to maximum in the state 2 and 3 specimens.

\section{X-Ray Diffraction Analysis}

Texture analysis carried out in the work by Kaibyshev et al. (1994) reveals that in different states of the magnesium alloy the evolution of CT is different. It shows that changes in deformation mechanisms, phenomenology, and kinetics of DRX depend on CT.

In the longitudinal specimens, the original texture maximum spreads in the initial stage of plastic flow and again becomes almost axial during further deformation. The maximum is shifted to the center of the direct pole figure.

In the state 2 specimens, small amount of strain $(\varepsilon=25 \%)$ gives rise to three maxima symmetrically arranged near the compression direction and deviated at an angle of $40-50^{\circ}$ from it. The increase in deformation shifts the texture maxima to the compression axis. When the amount of strain is $\varepsilon=75 \%$, a nearly axial basal texture is formed. 
At any strain, the CT of the state 3 specimens remains almost axial. The most significant changes occur at the early stage of plastic flow, when two maxima deflected through $45^{\circ}$ from the center of the pole figure are formed. Further increase in the amount of strain shifts the maxima to the center of the direct pole figure. When the amount of strain is $\varepsilon=75 \%$, the texture maxima retain their positions, but they significantly spread in the transverse direction.

We have calculated the maximal values of the Schmid factor for all possible slip systems in the MA14 alloy $(c / a=1.623)$ (Kaibyshev et al., 1994). The X-ray diffraction analysis shows that the greatest number of slip systems may be activated in state 3 in the original state and in the stage of plastic flow $\varepsilon=15 \%$. In state 1 , the possibility for such an occurrence appears at strains close to $\varepsilon=50 \%$. In state 2 the possibility for the activation of the greatest number of slip systems appears at $\varepsilon=25 \%$, but it is very short. The possibility for the activation of $c+a$ slip occurs in all states after large amounts of strain.

\section{DISCUSSION}

The analysis of experimental results gives evidence of the existing dependence between the character of plastic flow and parameters of recrystallized structure in specimens differing in CT. This is connected with the influence of texture on the mechanisms of plastic deformation and DRX. The diversity of values of the apparent activation energy, flow stress exponent and the nature of differences in mechanical properties of specimens with different CT is clear evidence of marked dissimilarity of the processes by which the recrystallized grains are formed in the MA14 alloy. This is explained by the presence of the easiest slip system $\langle 12 \overline{1} 0\rangle(0001)$ and by the low symmetry of the crystal lattice in $\mathrm{Mg}$ and its alloys. At the investigated temperature, the ratios of the critical resolved stresses $\tau_{\text {cr }}$ between the nonbasal and the basal planes (about 10) causes the strongest dependence of the character plastic flow on the Schmid factor (Rozenberg, 1967; Bakhteeva and Levit, 1983; Kaibyshev et al., 1985). This results in the critical importance of the CT for determining the type and nature of the crystallographic slip. In turn, the predominant plastic deformation mechanism controls the development of the DRX and determines its 
parameters, phenomenology, and kinetics. Now we consider the influence of texture on the mechanisms of DRX in detail.

\section{Influence of Texture on DRX}

Experimental results testify that the evolution of microstructure, CT and character of slip is interrelated with the amount of strain in MA14 alloy specimens differing in their original texture. In consequence, the effect of initial texture on DRX is caused by its influence on the character of dislocation slip. In turn, the operating deformation mechanism controls the recrystallization process. Comparison of the kinetics of structural changes and the active mechanisms of plastic deformation (Fig. 3) indicates the existence of stable correlation between them.

In the longitudinal specimens, the slip of $\boldsymbol{a}$ dislocation on prismatic and first kind pyramidal planes predominates in the early stage of deformation. The basal slip is difficult because of the low value of the Schmid factor, which results in high stresses in the state 1 specimens. Further deformation on nonbasal planes leads to a texture spread. As a result, the value of the Schmid factor increases and basal slip becomes easier. Localization of basal slip leads to the appearance of a peak on the $\sigma-\varepsilon$ curve.

DRX occurs after strain $\varepsilon \approx 15 \%$. According to the analysis of the deformation relief, recrystallized grain boundaries are formed predominantly in the place of slip bands. However, in the early stage of deformation in the longitudinal specimens, slip is homogeneous and slip bands are not formed. Therefore, the rate of DRX is low. The slip bands appear as a result of activation of the basal slip. With increasing strain, the basal slip starts to operate and the rate of DRX rises sharply. Acceleration of the recrystallization processes with activation of the basal slip is connected with the appearance of conditions for cross slip by the Friedel-Escaig mechanism and the action of the basal slip, resulting in the formation of slip bands. Let us consider the latter in detail.

Action of the basal slip results in the formation of a pinned node of dislocation lines (Predvoditelev and Troitskii, 1973) by the reaction

$$
\frac{1}{3}[21 \overline{1} 0]+\frac{1}{3}[12 \overline{1} 0]=\frac{1}{3}[11 \overline{2} 0] \text {. }
$$


The formation of pinned nodes leads to the generation of open dislocation loops (Couret and Caillard, 1985). Their edge components move at a rate that is two orders of magnitude greater than a screw component (Couret and Caillard, 1985). Their fast motion gives rise to a greater number of Frank-Read sources spaced some distance apart (Fig. 7). Because of this, a slip band passes through the entire grain for a short time. Near the original grain boundaries, the macroscopically observable deformation bands give way to the walls of the edge components of $\boldsymbol{a}$ dislocations lying in the basal plane. Since the screw components of the open loops of these dislocations experience cross slip by the Friedel-Escaig mechanism, they cease to be straight and transform to edge dislocations lying in the first kind pyramidal or prismatic planes (Couret and Caillard, 1985). As these dislocations climb (Milicka et al., 1970) they are incorporated in the existing walls, and are transformed into tilt subboundaries. For one reason or another, some of them become immobile and serve as sites for the formation of high-angle grain boundaries. This explains why the slip bands coincide with the newly formed boundaries of recrystallized grains. The subboundaries not pinned by second-phase particles climb on prismatic planes and merge with the immobile subboundaries. This provides fast buildup of misorientations because the reaction involves dislocations with a Burgers vector of the same direction, that leads to

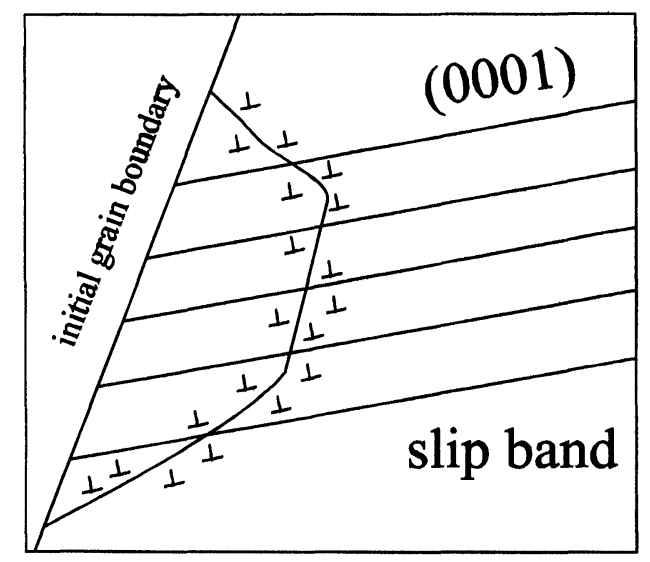

FIGURE 7 Formation of a high-angle boundary in the place of slip band by the Friedel-Escaig mechanism. 
an increase in the tensor density of dislocations, $\boldsymbol{B}(\boldsymbol{i}, \boldsymbol{j})$, proportionally to the increase in their scalar density. Owing to this mechanism of DRX, the boundaries of new grains are formed, and the tilt component plays a decisive role in their misorientation.

From Fig. 6 it is seen that low-angle grain boundaries in the unrecrystallized region exist together with high-angle recrystallized grain boundaries. These subgrain boundaries consisting of $a$ dislocation edge components quickly increase misorientation at the expense of confluence with mobile subgrain boundaries. Misorientations of some recrystallized grain boundaries are close to maximum. In the state 1 specimens, misorientation of recrystallized grain boundaries at strain $\varepsilon=40 \%$ does not exceed $60^{\circ}$, testifying that the mechanism resulting in maximum rate of DRX starts to operate later, than in states 1 and 3. In the state 2 specimens, misorientations become maximum after significant strains $(\varepsilon=75 \%)$.

The present mechanism leads to the maximum rate of DRX after strain $\varepsilon \approx 25 \%$ in the longitudinal specimens and in early stages of deformation in the transverse specimens. The change of acting deformation mechanisms in comparison with the states 1 and 3 specimens is responsible for the minimal rate of DRX in state 2 at a strain of $\varepsilon<40 \%$. The analysis of the deformation pattern and fine structure shows that minimum number of slip systems acts in this case. The basal and prismatic slips of $\boldsymbol{a}$ dislocation occur. The basal slip is predominant. The prismatic slip reveals signs of the cross slip by the Friedel mechanism. Under existing conditions the action of DRX mechanism controlled by cross slip according to the Friedel-Escaig mechanism is not possible. As a result, the rate of DRX is very low.

On the basis of the above conducted analysis of deformation mechanisms and DRX mechanisms it can be concluded that DRX proceeds at the maximum rate under the following conditions:

(i) cross-slip bands are formed by reaction (1);

(ii) favorable conditions exist for the motion of an $\boldsymbol{a}$ dislocation on both basal and nonbasal planes and cross slip occurs by the Friedel-Escaig mechanism;

(iii) $\langle 11 \overline{2} 0\rangle\{10 \overline{1} 1\}$ slip takes place.

The kinetics of DRX is affected most of all under condition (ii). If plastic deformation evolves predominantly owing to the motion of the 
basal $a$ dislocations and cross slip occurs by the Friedel model, then DRX will be a slow process. In the case of a fully homogeneous slip (non-fulfillment of condition (i)), the average path length for dislocation climb increases. Additional time is required for dislocations to align themselves in subboundaries. In consequence, recrystallization slows down. Such a situation may arise in the early stage of plastic flow in state 1 and in the strain range $\varepsilon=25-50 \%$ in state 3 .

Thus, the crystallographic texture strongly affects the DRX in MA14 alloy. This influence is due to differences in the slip character. The unequal possibilities of slip in specimens with different texture lead to action of different deformation mechanisms and dependence of DRX on the texture.

\section{CONCLUSION}

(1) The crystallographic texture affects DRX in the magnesium alloy. If basal planes locate in parallel or at right angles to the compression axis an extensive recrystallization process is observed. If basal planes locate at $45^{\circ}$ to the compression axis DRX occurs slowly and the formed grain size is less as compared with the two other cases.

(2) The influence of texture on DRX is related with changes in the deformation mechanisms, which control DRX mechanisms. The highest rate of DRX is ensured by a mechanism associated with the formation of a band of Frank-Read sources and the cross slip of the dislocation loop components by the Friedel-Escaig mechanism. This mechanism occurs if favorable conditions exist for the slip of $a$ dislocation on basal, prismatic and first kind pyramidal planes and cross-slip bands are formed. When DRX is controlled by cross slip according to the Friedel mechanism, recrystallization is a slow process. Only two slip systems act in this case: dominating basal and prismatic slip of $\boldsymbol{a}$ dislocations.

\section{References}

Bakhteeva, N.D. and Levit, V.I. (1983). The influence of temperature and deformation rate on the dynamic recrystallization of the KhN77TYuR alloy. Phys. Met. Metallogr., 55(4), 761-767. 
Bakhteeva, N.D., Vinogradova, N.1., Levit, V.I., Smirnov, L.V. and Filipov, Y.I. (1982). Dynamic recrystallization in high-temperature tension of a KhN77TYuR alloy single crystal. Phys. Met. Metallogr., 54(1), 149-158.

Belyakov, A.N., Kazakulov, I.Ya., Kaibyshev, R.O. and Sokolov, B.K. (1995). Dynamic recrystallization in a Fe-3\% Si steel. Phys. Met. Metallogr., 79(2), 114-122.

Borodkina, M.M. and Spektor, E.N. (1981). Rentgenograficheskii Analiz Tekstury Metallov $i$ Splavov (X-ray Diffraction Analysis of Texture of Metals and Alloys), p. 272. Moscow: Metallurgiya.

Bushnev, L.S., Kolobov, Y.R. and Myshlyev, M.M. (1989). Osnovy Elektronnoi Microscopii (Fundamentals of Electron Microscopy), p. 218. Tomsk: Izd-vo Tom. Un-ta.

Cadek, J. (1984). Crepp Kovovych Materialu (Creep of Metal Materials), p. 304. Praque: Academia.

Couret, A. and Caillard, D. (1985). An in situ study of prismatic glide in magnesium: 1. The rate controlling mechanism; 2. Microscopic activation parameters. Acta Metall., 33(5), 1447-1462.

Edelin, G. and Poirier, J.R. (1973). Etude de la montee des dislocations au moyen d'experiences de fluage part diffusion dans le magnesium. Philos. Mag., 28, 1211-1223.

Grabski, M.W. (1972). Nadplastycznosc Strukturalna Metali (Structural Superplasticity of Metals), p. 270. Katowice: Slask.

Kaibyshev, O.A. (1992). Superplasticity of Alloys, Intermetallides, and Ceramics, p. 317. Berlin: Springer.

Kaibyshev, R.O., Galiyev, A.M., and Sokolov, B.K. (1994). Effect of plastic deformation on texture, crystallographic slip and structural changes in a magnesium alloy. Phys. Met. Metallogr., 78(2), 221-231.

Kaibyshev, O.A., Kazachkov, I.V. and Zaripov, N.G. (1985). The influence of texture on superplasticity. Dokl. Akad. Nauk SSSR, 282(3), 594-598.

Kaibyshev, R.O. and Sitdikov, O.Sh. (1991). Phenomenology and mechanisms of dynamic recrystallization of magnesium. Dokl. Akad. Nauk SSSR, 321, 306-309.

Kaibyshev, R.O., Sokolov, B.K. and Galiyev, A.M. (1994). Effect of slip homogeneity on the dynamic recrystallization of a magnesium alloy. Dokl. Akad. Nauk SSSR, 337(6), 737-740.

Maki, T., Akasaka, K., Okuno, K. and Tamura, I. (1982). Dynamic recrystallization of austenite in 18-8 stainless steel and 18Ni maraging steel. Trans. ISIJ, 22(4), 253-261.

Milicka, K., Cadek, J. and Rys, P. (1970). High temperature creep mechanisms in magnesium. Acta Metall., 18(10), 1071-1082.

Ouchi, C. and Okita, T. (1982). Dynamic recrystallization behavior in austenitic Nbbearing high strength low alloy steel and stainless steel. Trans. ISIJ, 22(7), 543-547.

Pickence, J.R., Langan, T.J., England, R.O. and Liebson, M. (1987). A study of the hotworking behavior of SiC-AI alloy composites and their matrix alloys by hot torsion testing. Metall. Trans. A, 18(2), 303-312.

Predvaditelev, A.A. and Troitskii, O.A. (1973). Dislokatsii $i$ Tochechnye Defekty $v$ Geksagonal'nykh Metallakh (Dislocations and Point Defects in Hexagonal Metals), p. 200. Moscow: Atomizdat.

Puschl, W., Schoeck, G. and Kirchner, H.O.K. (1987). The line tension of dislocations in anisotropic media. Philos. Mag., 56(4), 553-563.

Rozenberg, V.M. (1967). Polzuchest' Metallov (Creep of Metals), p. 267. Moscow: Metallurgiya.

Sah, J.P., Richardson, C.J. and Sellars, C.M. (1974). Grain-size effects during dynamic recrystallization of nickel. Met. Sci. J., 8(4), 325-331.

Sakai, T. and Jonas, J.J. (1984). Dynamic recrystallization mechanical and microstructural considerations. Acta Metall., 32(2), 189-209.

Vagarli, S. and Langdon, T.G. (1981). Deformation mechanisms in HCP metals at elevated temperatures: I. Creep behavior of magnesium. Acta Metall., 29(6), 1969-1982. 
Vagarli, S. and Langdon, T.G. (1982). Deformation mechanisms in HCP metals at elevated temperatures: II. Creep behavior of a $\mathrm{Mg}-0.8 \% \mathrm{Al}$ solid solution alloys. Acta Metall., 30(4), 1157-1170.

Valiev, R.Z., Vergazov, A.N. and Gercman, V.Y. (1991). Kristallogeometricheskii Analiz Mejkristallitnyh Granic v Praktike Elektronnoi Mikroskopii (Crystallogeometrical Analysis of Intercrystalline boundaries in Practice of Electron Microscopy), p. 280. Moscow: Nauka.

Yoo, M.N. (1981). Slip, twinning and fracture in hexagonal close-packed metals. Metall. Trans. A, 12(3), 409-418. 